\title{
Student satisfaction as an element of education quality monitoring in innovative higher education institution
}

\author{
Elena Razinkina ${ }^{1}$, Ludmila Pankova $^{2}$, Irina Trostinskaya ${ }^{3}$, Elena Pozdeeva ${ }^{3}$, Lidiya \\ Evseeva $^{3}$, and Anna Tanova ${ }^{3, *}$ \\ ${ }^{1}$ Peter the Great St. Petersburg Polytechnic University, Rectors Office, 195251 St.-Petersburg, Russia \\ ${ }^{2}$ Peter the Great St. Petersburg Polytechnic University, Basic Educational Programmes Department, \\ 195251 St.-Petersburg, Russia \\ ${ }^{3}$ Peter the Great St. Petersburg Polytechnic University, Advertising and Public Relations Department, \\ 195251 St.-Petersburg, Russia
}

\begin{abstract}
Topicality of the research is confirmed by increasing student involvement into the educational process, when not only the academic staff and administration participate in the improvement of higher education institution's activity, but also education customers - students. This adds a new dimension to the issue of monitoring education quality and student satisfaction with higher education. This issue echoes the ideas of $M$. Weber about the relationship between such components as cognitive motivation, personal development and student satisfaction with higher education. Besides, it is essential to focus on the approach of R. Barnet to defining the quality of education with the emphasis on a priority of development of an educational institution as the system that meets customers' needs. Monitoring student satisfaction with education quality has become an integral part of the educational process not only in a number of European universities, which have used this monitoring for decades, but also in Russian universities, which are interested in education quality improvement. Leading universities in Russia, including Peter the Great St. Petersburg Polytechnic University, are implementing policies targeted at increasing student satisfaction with higher education quality. Education quality monitoring as a key element in the system of providing feedback to students contributes greatly to this process.
\end{abstract}

\section{Introduction}

Global civilizational changes increase the value of the scientific and technological potential in the society. Information, knowledge, scientific breakthroughs become a significant resource in the unifying medium that bonds people and technology. Therefore, great importance is attached to the issues related to transformations of roles common for subjects in the educational space and an increase in the professional potential of university graduates. All the above-mentioned considers the quality of professional education as the priority trend

\footnotetext{
* Corresponding author: tanovaann@mail.ru
} 
for competitive professional training and makes educational institutions actual subjects of the market, capable of accumulating their competitive advantages to improve the education quality.

Expansion of the higher education system in Russia, changes in its structure and content are caused by its increasing contribution into the economic progress, by the improvement of living standards, and by the rising demand for qualified staff. The society development trends, determined by the fourth industrial revolution, imply modification of educational strategies and building a new cultural and educational model. All these prerequisites make monitoring in the education quality management, including student satisfaction monitoring, relevant to the today's situation.

The object of this research is students, as they have always been the most responsive part of the young generation. They are the social community capable of bringing educational innovations into the economy. Both student responsiveness and good education lead to further social activity. Integrated into the social structure of the society, the student community shows their aspiration for personal and professional identity, creativity, involvement into socio-economic and cultural reforms.

It is worth noting that global acceleration and extensive accumulation of new information and communication products surge the demand for specialists who would be knowledgeable, broad-minded, flexible, capable of adapting their occupational fields to market needs and to the necessity to change their personal or professional preferences, who would be skilled at dealing with information and knowledge, adopting high-tech products to achieve their life goals. Therefore modern workers should continuously enhance quality, their personal and professional skills. Global information environments ensure emergence of new knowledge, relevant to challenges of the technogenic civilization.

According to M. Weber, the goal of a higher education institution is to form and to anchor in the student perception the so-called "philosophy of life", their future role as researchers and lecturers, which was the key role for M. Weber at the turn of the century. He saw the supreme purpose in serving the science, being committed to the common cause, aspiring to acquire knowledge. All this is correlated with the student satisfaction with higher education and issues of student personal development [1].

\section{Problem setting}

As early as 1970s European universities were aware of the necessity to analyze student satisfaction with their academic program to achieve their educational goals [2]. At present there has been accumulated great experience of satisfaction monitoring studies: in Europe they amount to 30 years, in UK - 20 years [3]. The monitoring research has contributed to the modern trend and set the course for new research. However, the Russian experience in the area of education research is insufficient.

Satisfaction monitoring is based on studying student satisfaction feedback, which is a sign of successful performance for a higher educational institution [4]. Student satisfaction feedback is defined as opinions of students about the service they receive as students. This may include perceptions about the learning and teaching, organization of the educational process, the learning support facilities, the learning environment [5]. International researchers agree that the student feedback, which is assiduously collected in higher education institutions, will contribute to continuous education quality improvement. Along with public information data, the research helps upgrade education management. Public awareness also matters: it forms a new student culture based on their participation in management. Students have to be sure that changes in their universities are caused by the feedback they show in the polls. Criteria for measuring satisfaction depend on the university 
profile. For instance, researchers at the School of Business and Law, Liverpool John Moores University, provided 60 variables that influence student satisfaction [6].

In Russia opinion polls illustrate that university studies discourage a number of students and make them disappointed at their chosen occupational field [7]. This fact forces major Russian universities to do comprehensive research into factors and indicators of student satisfaction with education quality.

Satisfaction with the quality of engineering education is significant in preparing a qualified innovation-oriented engineer who possesses the main professional competence ability to create "human-dimensional" systems and apply "organizational creativity" [8].

Building a satisfaction model is based on the methodology of empirical interpretation, which implies searching for empirical elements [9]. Objectification of the "satisfaction" category means differentiation between satisfaction as the state of consciousness and satisfaction as the behavioral reaction. Moreover, satisfaction is defined as a derivative of a set of factors that reflect the synthesis of the value of a measured object and the quality of a measurer, i.e. a student.

The satisfaction model combines the results of satisfaction measurement in accordance with various parameters of the educational process and situation, behavioral aspects showing students' life strategies and their trajectories to fit into the labor market, and institutionally determined factors resulting from the trends of the modern educational paradigm. Student satisfaction with higher education and education quality measurement depend on student values and attitudes to education - incentives to study, value of education and knowledge.

The ultimate value of education can be defined by a number of the following meanings: ability development, cognitive needs, general literacy. Besides, the attitude to education is explained by the factors: belonging to different social groups, level of income, education of parents, modernization in the system of education. In total these factors determine the sociosituational aspect of the student attitude to education [10].

Satisfaction with higher education is a parameter characterizing the professional socialization process of students as subjects of the educational activity. The education satisfaction model consists of the following main elements: satisfaction with social status; satisfaction with the profession/area of expertise students are trained for; satisfaction with the educational process [11]. In addition, satisfaction with the curriculum may be viewed as an integrative indicator marking the degree of fulfillment of student social expectations from educational activities, formed during their professional socialization.

The importance of higher education satisfaction in the modern legal framework makes it urgent to measure the quality of educational services on a regular basis, which is possible when combining the statistical and sociological approaches implemented in the form of monitoring. Monitoring satisfaction as part of sociological research in the system of education quality management enables getting the full picture of student attitude to education and characterizing the educational environment, putting special emphasis on such aspects as: satisfaction with student life and the selected higher education institution; with the educational process; participation in extra-curricular activities; the productivity of awareness-raising activities [12].

The practice of conducting education satisfaction surveys at engineering universities and colleges shows that satisfaction is considered as comprehensive assessment primarily based on the motivational aspect, whose positive parameters correspond with satisfaction indicators (surveys carried out at engineering universities and colleges in the Tyumen region, The Republic of Bashkortostan and the Republic of Komi) [13].

According to the survey, first year students of Siberian State Technological University assess the peculiarities of studying at university in comparison with school quite adequately and they also see the special features of university education, especially in terms of greater independence. They also note the need for free creative activities both during the classes and 
after. It is evident that freedom is the most important prerequisite for the development of a self-actualizing creative person. Thus, ensuring freedom to obtain satisfaction with the educational process, society can, on the one hand, help individuals to satisfy their needs, and on the other - provide students with an opportunity for self-development and responsibility enhancement [14].

Quality, as one of the key indicators of a successful higher education institution, is viewed here as a number of characteristics of an educational service, which result in the necessary skills and expertise gained by university graduates. In this respect, the quality of educational services is the major concern of the market, which is defined by competitiveness of the educational establishment and is summarized in the form of academic rankings [15]. According to R. Barnet, three main approaches, characterizing quality, are agreed upon today: the objectivist, relativist and developing [16]. Integrating these approaches helps to describe the activities of an educational establishment as a system (its systemic measurable qualities), it enables weighing the achievements in a multi-tasking environment and indicating the strategic area of development towards the utmost satisfaction of consumer needs.

When measuring quality, customer satisfaction with educational services serves as the core element, as establishments depend on their consumers, and they have to take into account their needs and interests, fulfill their requirements and try to exceed their expectations [17]. The most significant areas of consumer monitoring, used to study satisfaction and quality assessment, lie in defining the indicators connected with external consumers (school-leavers, parents, employers); measuring the quality of the teaching process; defining the indicators reflecting students' progress.

At Peter the Great St. Petersburg Polytechnic University (SPbPU) student surveys are frequently carried out as online and paper questionnaires, which enables monitoring student satisfaction with education. The survey aimed to analyze the quality of educational programs offered at SPbPU was conducted in May and June 2017. The comprehensive assessment was based on the concept of satisfaction with education, in which satisfaction is formed as a result of systemic interaction between the following parameters:

- Correlation between the education received and the expectations of a student;

- Intentions of students in terms of further employment with regard to their field of studies;

- Opportunities for creativity and self-fulfillment offered by the University while studying, gaining skills and knowledge relevant for the current market situation;

- Wide and adequate information support, as well as support from the teaching staff and other university employees;

- Sufficient facilities;

- $\quad$ Satisfaction with the formal procedures accompanying the studying process;

- Comfortable environment for communication.

The following important factors were also taken into consideration in the survey: the high profile of the University, scientific focus of education, the opportunity to study foreign languages, the possibility to meet interesting people and take part in various projects, which is a top priority for leading universities and is especially welcomed by young people hoping to build up successful careers. In the questionnaire a lot of attention was drawn to the student awareness indicator, which does not only show the degree of involvement in the educational process, but it also defines the quality of work done by academic bodies and the supervisors of educational programs.

The given research was based on the main hypothesis that the quality assessment of a certain educational program directly depends on the fact how well a student is informed about the opportunities offered by various academic bodies of the University.

The following assumptions acted as complimentary hypotheses: 
- Student satisfaction is influenced by insufficient awareness of certain separate elements of academic programs, which have been introduced only recently or those that have undergone innovative changes, such as project-based learning, distance learning, optional subjects;

- Being aimed at finding employment connected with their area of studies, students put a special emphasis on a practice-oriented approach to education.

\section{Monitoring results}

4040 students took part in the survey, representing all the institutes which SPbPU comprises.

First of all, it should be mentioned that, on the whole, the results of the survey demonstrate quite a high level of student satisfaction with education, i.e. $66 \%$ of the surveyed students (see fig.1). There is interconnection between the indicators on which the parameters of the concept of student satisfaction are based. Thus, $65 \%$ of the students replied that education lived up to their expectations, $68 \%$ of students had a clear vision of their future jobs, $64 \%$ of respondents were going to look for a job closely connected with their area of studies and $82 \%$ confirmed the fact that they had made an informed choice to study a certain field. These data show that more than $2 / 3$ of students are implementing the strategy of practice-oriented training, gaining skills and knowledge relevant for the current market situation.

\section{Are you satisfied with the quality of education at SPbPU?}

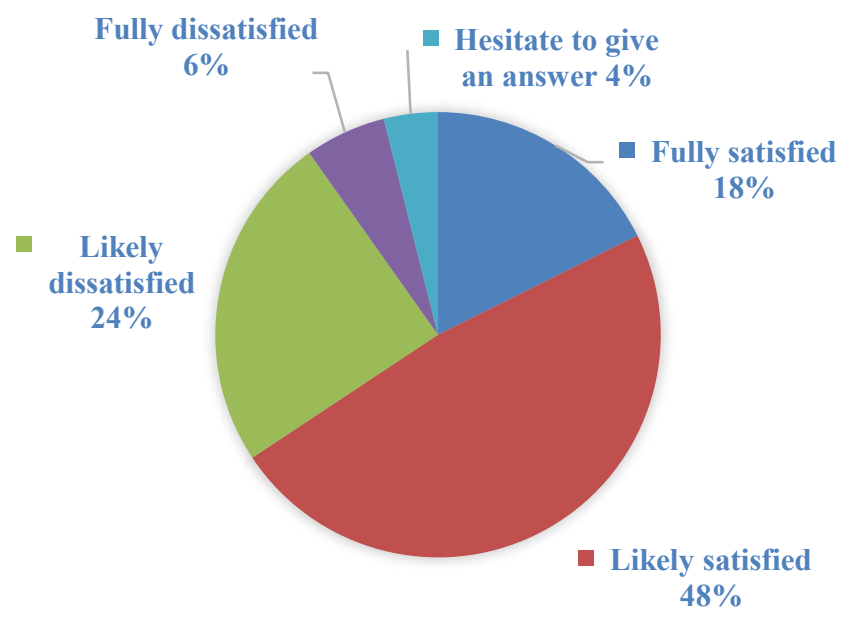

Fig. 1. Satisfaction with the quality of education at SPbPU 
The practice-oriented approach to education is confirmed by the fact that students do various internships while studying at the Polytechnic University. Thus, only $8 \%$ of the students said that they were not doing an internship, while $92 \%$ of respondents replied that establishments where students could do an internship were chosen either by the University $(12 \%)$, or by the students themselves (22\%), or both ways were possible (52\%) (see fig. 2 ).

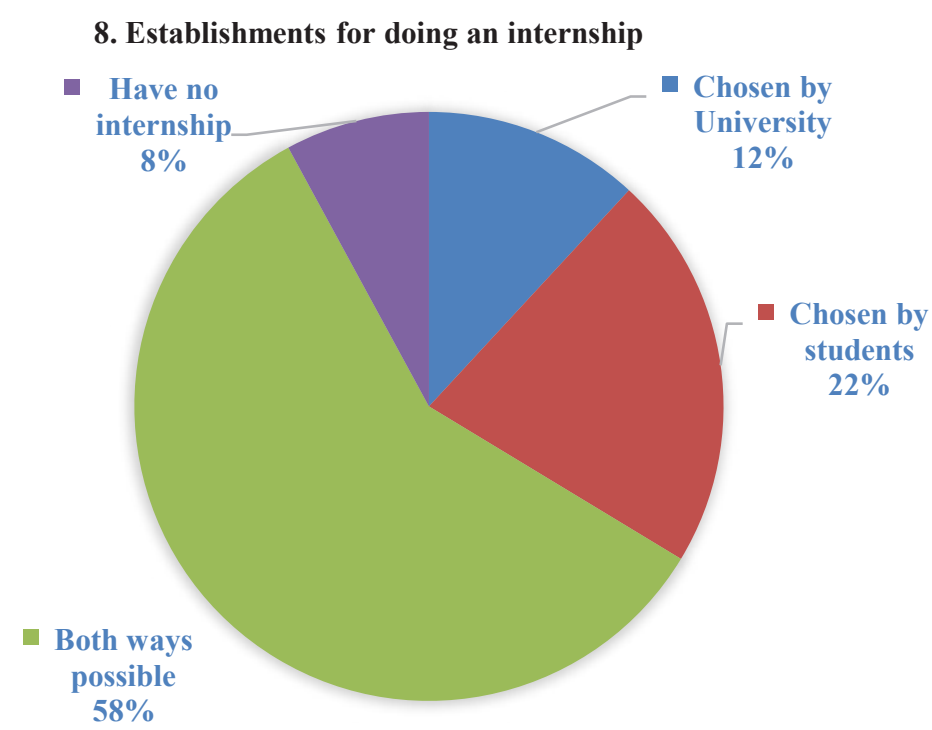

Fig. 2. Establishments for doing an internship.

Efficiency of an internship regarding the future employment connected with their current field of studies was mentioned by $68 \%$ of the students.

Extra-curricular activities also serve as a significant indicator of student satisfaction with education. Research has shown that on the whole $36 \%$ of the students are satisfied with the way leisure activities are organized (they gave 4-5 points), 34\% awarded 2-3 points, and 30\% of respondents gave 1 point and less (see Table 1). The results of numerous surveys demonstrate the fact that, as a rule, about one third of students take an active part in extracurricular activities, while the rest of the students consider the way leisure activities are organized not as participants, but as spectators, attending the events held at the University.

When assessing the university facilities, the focus was on the following indicators: the condition of classrooms, infrastructure for social and cultural events, sporting facilities and equipment, the availability of various facilities and equipment (see Table 1). The results of the survey show that the availability of various facilities and equipment is not highly evaluated by the students, most of them giving 2 or 3 points to this parameter. This testifies the fact that, enjoying an outstanding reputation among students $(80 \%$ and $58 \%$ of the respondents respectively replied that the high profile of the University and the education received there are worth 4-5 points), SPbPU still has room for improvement and that it should concentrate on developing its facilities. 
Table 1. Assessment of Various Aspects of Educational Activities at the University.

\begin{tabular}{|l|c|c|c|}
\hline & $0-1$ points & $2-3$ points & $4-5$ points \\
\hline $\begin{array}{l}\text { The condition of the } \\
\text { infrastructure for social } \\
\text { and cultural events }\end{array}$ & 25 & 33 & 43 \\
\hline $\begin{array}{l}\text { The condition of gyms and } \\
\text { other sporting facilities }\end{array}$ & 27 & 41 & 32 \\
\hline $\begin{array}{l}\text { The opportunity to use } \\
\text { gyms and other sporting } \\
\text { facilities }\end{array}$ & 18 & 38 & 31 \\
\hline $\begin{array}{l}\text { The condition of } \\
\text { classrooms }\end{array}$ & 16 & 45 & 39 \\
\hline $\begin{array}{l}\text { The availability of various } \\
\text { facilities and equipment }\end{array}$ & 30 & 34 & 36 \\
\hline $\begin{array}{l}\text { Leisure activities for } \\
\text { students }\end{array}$ & & 49 & 39 \\
\hline
\end{tabular}

Another area for further development may be found in the field of innovative educational technologies, including distance learning, project-based learning and optional subjects within a mobility module, as well as information support for these processes. To illustrate this statement with the help of some research results, it can be mentioned that $26 \%$ of the respondents approve of distance learning technologies, $40 \%$ do not approve and $34 \%$ are undecided. $79 \%$ of the respondents are unaware of the opportunity to select certain subjects within a mobility module (and $21 \%$ are, on the contrary, informed about it), $81 \%$ know nothing about project-based learning (19\% claim the opposite).

\section{Conclusions}

The general conclusions based on the given research make it possible to admit that the sociological monitoring has justified expectations, as it has shown student satisfaction with higher education received at Peter the Great St. Petersburg Polytechnic University, and it has also highlighted some problem areas, as well as areas for further development. Further quality enhancement is primarily connected with the systemic development of facilities and equipment as a significant component of the educational process, increasing flexibility and individualization of the educational process by means of electronic and distance-learning technologies, offering more opportunities for practice-oriented learning, more active information support covering the advantages of innovations introduced, opportunities for self-development resulting from project-based learning, extra-curricular and leisure activities for students.

To sum it up, it should be mentioned that the hypotheses (the main one and the complimentary ones) proposed at the beginning of the given research were primarily confirmed when analyzing the results of the survey, therefore, the purpose and the tasks of the research have been fulfilled, which confirms its value and scientific prospects, as well as the fact that surveying can be further applied as an efficient tool for monitoring the quality of education.

\section{References}

1. M. Weber, Self-Consciousness of European Culture of the 20th Century (Politizdat, Moscow, 1991) 
2. B. R. Morstain, Journal of Higher Education, 1, 1 (1977)

3. V. A. Zotova, Journal of Creative economics, 11 (3), 303 (2017)

4. M. Shah, C. Nair, J. Richardson, Measuring and enhancing the student experience (Chandos Publishing, Cambridge, 2017)

5. L. Harvey, Journal of Quality in Higher Education, 9 (1), 3 (2003)

6. J. Douglas, A. Douglas, B. Barnes, Journal of Quality Assurance in Education, 14 (3), 251 (2006)

7. D. L. Konstantinovsky, Education and science in Russia: state and development potential (Center for Sociological Research, Moscow, 2016)

8. A. L. Andreev, Education and science in Russia: state and development potential (Center for Sociological Research, Moscow, 2016)

9. V. A. Yadov, Strategy of sociological research. Description, explanation, understanding of social reality (Dobrosvet, Book house University, Moscow, 1998)

10. Yu. A. Zubok, V.I. Chuprov, Journal of Sociological research, 8, 103 (2012)

11. A. S. Spassky, Journal of Innovations in education, 5, 63 (2003)

12. N. P. Makarkin, Monitoring of students' satisfaction with educational process (Publishing house Mordovian University, Saransk, 2007)

13. S. Yu. Frolov, Journal of Theory and practice of social development, 4 (2015)

14. A. V. Andrienko, Journal of Siberian Medical Sciences, 1 (2007)

15. N. A. Bonyushko, A. A. Semchenko, Journal of Omsk Scientific Bulletin. Series "Society. History. Modernity", 3 (129), 31 (2014)

16. R. Barnet, Improving higher education: total quality care (SRHE and Open University Press, 1992)

17. S. S. Kotova, I. I. Hasanova, Journal of Education and Science, 9, 43 (2016) 